\title{
Pregnancy disorders leading to very preterm birth influence neonatal outcomes: results of the population-based ACTION cohort study
}

\author{
Luigi Gagliardi', Franca Rusconi², Monica Da Frè3, Giorgio Mello ${ }^{4}$, Virgilio Carnielli5, Domenico Di Lallo ${ }^{6}$, Francesco Macagno \\ Silvana Miniaci ${ }^{8}$, Carlo Corchia ${ }^{9}$ and Marina Cuttini ${ }^{10}$
}

BACKGROUND: We examined the relationships between pregnancy disorders leading to very preterm birth (spontaneous preterm labor, prelabor premature rupture of membranes (PPROM), hypertension/preeclampsia, intrauterine growth restriction (IUGR), antenatal hemorrhage, and maternal infection), both in isolation and grouped together as "disorders of placentation" (hypertensive disorders and IUGR) vs. "presumed infection/inflammation" (all the others), and several unfavorable neonatal outcomes.

METHODS: We examined a population-based prospective cohort of 2,085 singleton infants of 23-31 wk gestational age (GA) born in six Italian regions (the Accesso alle Cure e Terapie Intensive Ostetriche e Neonatali (ACTION) study).

RESULTS: Neonates born following disorders of placentation had a higher GA and better overall outcomes than those born following infection/inflammation. After adjustment for GA, however, they showed higher risk of mortality (odds ratio, OR: 1.4; 95\% confidence interval, Cl: 1.0-2.0), bronchopulmonary dysplasia (BPD) (OR: 2.5; Cl: 1.8-3.6), and retinopathy of prematurity (ROP) (OR: 2.0; Cl: 1.1-3.5), especially in growth-restricted infants, and a lower risk of intraventricular hemorrhage (IVH) (OR: 0.5; Cl: 0.3-0.8) and periventricular leukomalacia (PVL) (OR: 0.6; Cl: 0.4-1.1) as compared with infants born following infection/inflammation disorders.

CONCLUSION: Our data confirm the hypothesis that, in very preterm infants, adverse outcomes are both a function of immaturity (low GA) and of complications leading to preterm birth. The profile of risk is different in different pregnancy disorders.

nfants born very preterm have a high mortality and morbidity, and the increased risk is likely to reflect a combination of immaturity per se, and of the underlying pathologies causing preterm birth (1). However, disentangling the effect of these two components in clinical and in epidemiologic studies, and estimating the contribution of single pathological entities, remains difficult, and the results of the few epidemiologic studies investigating these aspects in terms of neonatal outcome are conflicting. Mortality, e.g., has been found to be higher $(2,3)$, lower $(4,5)$, or equal $(6)$ in preeclampsia as compared with spontaneous preterm labor. The same discrepancies occur for bronchopulmonary dysplasia (BPD) (7-10).

Although it is widely acknowledged that preterm birth is caused by several different pathophysiological processes (11), no consensus exists on their definition and classification. Studies on complications of pregnancies ending in very preterm birth, and their relationship to outcomes, are complicated by a taxonomy that mixes etiologic and clinical aspects. A classification that differentiates individual clinical presentations, even when sharing a common etiology (e.g., prelabor premature rupture of membranes (PPROM) and spontaneous preterm labor), is useful for clinicians to better tailor treatments to patients but can be detrimental in epidemiologic studies aimed at clarifying associations. Several years ago, Klebanoff and Shiono (12) proposed that most causes of preterm birth can be differentiated into "inside out" (primary abnormal placentation) and "bottom-up" (ascending infections), suggesting that these two categories, although partially overlapping, reflect different pathophysiologic pathways. Recently, McElrath et al. (3) combined, in a large cohort of births at $<28 \mathrm{wk}$ of gestation, clinical information with placental and bacteriological data. They found higher frequencies of placental histologic inflammation and presence of microorganisms in pregnancies complicated by preterm labor, PPROM, abruption, and cervical insufficiency, whereas preeclampsia and intrauterine growth restriction (IUGR) were accompanied by signs of poor placentation such as infarcts and abundance of syncytial knots. Therefore, they suggested that very preterm delivery can indeed be categorized into two broad groups: disorders of placentation and intrauterine infection/inflammation (3). 
We used the data of the ACTION (Accesso alle Cure e Terapie Intensive Ostetriche e Neonatali) project, a large population-based cohort study carried out in Italy in very preterm infants, to test the hypothesis that different pregnancy disorders that lead to very preterm delivery, considered in isolation or grouped together, are associated with different patterns of important adverse neonatal outcomes.

\section{RESULTS}

The cohort analyzed for this study included 2,085 singleton newborn infants. Spontaneous preterm labor was the most common complication leading to very preterm birth (628 cases; $30.1 \%$ ), followed by hypertensive disorders of pregnancy (441; $21.2 \%)$, PPROM $(355 ; 17.0 \%)$, antepartum hemorrhage
(253; 12.1\%), IUGR (198; 9.5\%), and maternal infection as an indication for delivery (73; 3.5\%). "Other" antecedents (e.g., prepregnancy chronic maternal diseases), suspected acute fetal distress, and unknown causes represented only $2 \%$ of cases each.

Table 1 shows the characteristics and outcomes of the infants by cause of birth. Overall, $77 \%$ of the infants received antenatal steroid prophylaxis, and $89 \%$ were delivered in level III centers. The groups differed for most of the characteristics reported. Infants born following spontaneous preterm labor had a lower gestational age (GA) than those in other groups. Together with those with antepartum hemorrhage, they were less frequently treated with antenatal steroids and delivered in level III centers, probably because of the sudden occurrence of

Table 1. Characteristics and outcomes of the infants studied according to main antenatal complications leading to preterm birth

\begin{tabular}{|c|c|c|c|c|c|c|c|c|c|c|c|}
\hline & $\begin{array}{c}\text { Spontaneous } \\
\text { preterm } \\
\text { labor } \\
n=628\end{array}$ & $\begin{array}{l}\text { Hypertensive } \\
\text { disorders } \\
n=441\end{array}$ & $\begin{array}{l}\text { PPROM } \\
n=355\end{array}$ & $\begin{array}{c}\text { Hemorrhage } \\
n=253\end{array}$ & $\begin{array}{c}\text { IUGR } \\
n=198\end{array}$ & $\begin{array}{c}\text { Maternal } \\
\text { infection } \\
n=73\end{array}$ & $\begin{array}{c}\text { Acute fetal } \\
\text { distress } \\
n=47\end{array}$ & $\begin{array}{c}\text { Other } \\
\text { causes } \\
n=47\end{array}$ & $\begin{array}{l}\text { Unknown } \\
n=43\end{array}$ & $\begin{array}{c}\text { Total } \\
N=2,085\end{array}$ & $P$ value \\
\hline \multicolumn{12}{|c|}{ Neonatal characteristics (mean (SD) or (\%)) } \\
\hline $\begin{array}{l}\text { Gestational } \\
\text { age }\end{array}$ & $27.5(2.5)$ & $29.1(1.8)$ & $28.4(2.2)$ & $28.8(2.0)$ & $29.3(1.7)$ & $27.6(2.4)$ & $29.6(1.4)$ & $28.9(2.5)$ & $28.7(2.3)$ & $28.4(2.3)$ & $<0.001$ \\
\hline $\begin{array}{l}\text { Birth } \\
\text { weight }\end{array}$ & $1,149(386)$ & $1,054(311)$ & $1,238(383)$ & $1,276(365)$ & $929(317)$ & $1,140(366)$ & $1,368(322)$ & $1,371(481)$ & $1,321(380)$ & $1,152(379)$ & $<0.001$ \\
\hline Males & 54.5 & 46.4 & 56.1 & 57.3 & 56.6 & 52.0 & 66.0 & 55.3 & 58.1 & 53.9 & 0.040 \\
\hline \multicolumn{12}{|c|}{ Prenatal and neonatal assistance (\%) } \\
\hline $\begin{array}{l}\text { Antenatal } \\
\text { steroids }\end{array}$ & 70.4 & 81.8 & 87.1 & 67.2 & 84.0 & 84.9 & 73.8 & 76.1 & 63.6 & 77.3 & $<0.001$ \\
\hline $\begin{array}{l}\text { Induced or } \\
\text { cesarean } \\
\text { birth }\end{array}$ & 30.7 & 99.3 & 70.9 & 96.4 & 99.5 & 73.6 & 100 & 89.4 & 85.0 & 72.1 & $<0.001$ \\
\hline $\begin{array}{l}\text { Born in } \\
\text { level III } \\
\text { center }\end{array}$ & 83.6 & 93.9 & 94.4 & 82.6 & 98.0 & 86.3 & 87.2 & 97.9 & 65.1 & 89.0 & $<0.001$ \\
\hline $\begin{array}{l}\text { Mechanical } \\
\text { ventilation }\end{array}$ & 64.6 & 60.0 & 54.1 & 70.7 & 60.4 & 63.9 & 57.5 & 67.4 & 67.5 & 62.1 & 0.005 \\
\hline \multicolumn{12}{|c|}{ Neonatal conditions (mean (SD) or (\%)) } \\
\hline $\begin{array}{l}\text { Apgar at } \\
5 \mathrm{~min}\end{array}$ & $7.1(2.0)$ & $7.8(1.5)$ & 7.7 (1.6) & $7.3(1.7)$ & $7.7(1.5)$ & $7.5(1.8)$ & $7.6(1.3)$ & $7.3(1.8)$ & $7.0(1.8)$ & $7.5(1.7)$ & $<0.001$ \\
\hline $\begin{array}{l}\text { Apgar at } \\
5 \mathrm{~min}<7\end{array}$ & 32.5 & 20.0 & 22.6 & 29.5 & 18.5 & 20.6 & 26.7 & 23.4 & 43.9 & 25.9 & $<0.001$ \\
\hline \multicolumn{12}{|l|}{ Outcomes (\%) } \\
\hline $\begin{array}{l}\text { Total } \\
\text { in-hospital } \\
\text { mortality }\end{array}$ & 20.2 & 7.7 & 14.2 & 12.3 & 14.7 & 17.8 & 6.4 & 10.6 & 16.3 & 14.3 & $<0.001$ \\
\hline $\begin{array}{l}\text { IVH, grade } \\
\text { III-IV }\end{array}$ & 15.6 & 2.8 & 6.8 & 7.3 & 4.2 & 8.7 & 6.4 & 8.7 & 16.7 & 8.6 & $<0.001$ \\
\hline Cystic PVL & 6.4 & 3.5 & 5.4 & 5.3 & 2.6 & 5.7 & 6.5 & 8.7 & 10.0 & 5.2 & 0.238 \\
\hline BPD & 13.1 & 14.2 & 10.5 & 10.7 & 15.4 & 15.0 & 13.0 & 9.5 & 15.6 & 12.8 & 0.752 \\
\hline $\begin{array}{l}\text { ROP, stage } \\
3-4 \text { or plus }\end{array}$ & 5.9 & 4.3 & 5.2 & 1.7 & 2.7 & 4.5 & 0.0 & 2.3 & 2.4 & 4.3 & 0.173 \\
\hline
\end{tabular}

Main antenatal complication has been identified by clinicians involved in the study according to a priori-defined mutually exclusive categories.

BPD, bronchopulmonary dysplasia; IUGR, intrauterine growth restriction; IVH, intraventricular hemorrhage; PPROM, prelabor premature rupture of membranes; PVL, periventricular leukomalacia; $R O P$, retinopathy of prematurity. 


\section{Articles | Gagliardiet al.}

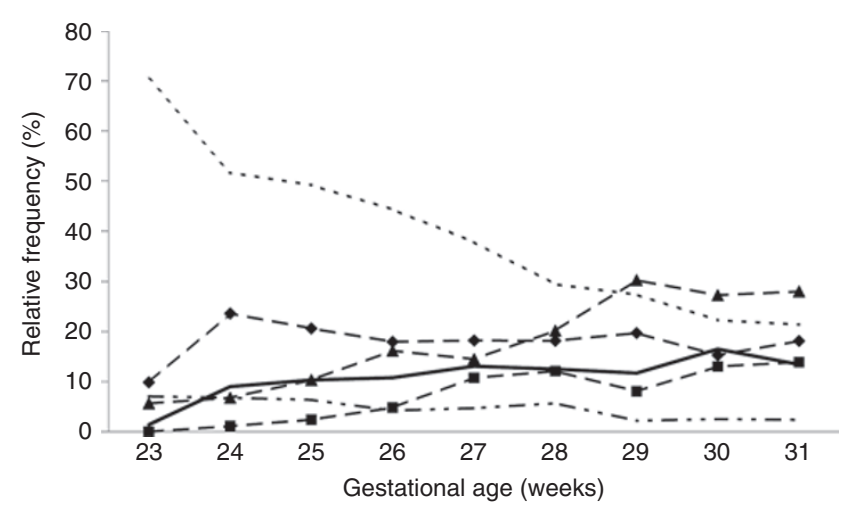

Figure 1. Frequency of main antenatal complications by gestational age. Short dashed line indicates spontaneous preterm labor; diamonds indicate prelabor premature rupture of membranes; squares indicate intrauterine growth restriction; triangles indicate hypertensive disorders; long and short dashed line indicates maternal infection; solid line indicates hemorrhage.

these conditions as compared with more "chronic" complications such as IUGR and PPROM.

The relative proportion of antecedents of birth differed by GA (Figure 1): spontaneous preterm labor steadily decreased in frequency with advancing GA, whereas hypertensive disorders, IUGR, and to a lesser extent, antepartum hemorrhage increased.

Table 2 reports the associations between individual antecedents of preterm birth and outcomes, with or without adjustment for GA. Spontaneous preterm labor was used as the reference category. Adjustment for GA drastically changed the odds ratios (ORs), and often even the direction of the association (from $<1$ to $>1$ ). In particular, because infants born following hypertension and IUGR had higher GA, an association emerged between these pathologies and BPD, mortality (only for IUGR), and retinopathy of prematurity (ROP) (only for hypertension). The effect of a further adjustment for sex and antenatal steroids was negligible (data not shown).

Restricting the analysis to survivors until discharge did not appreciably change the estimated ORs (data not shown), indicating that selection as a result of survival was not a major influential factor.

In Table 3, the main antecedents of preterm birth are grouped into two categories according to McElrath et al. (3). Presumed infection/inflammation, including spontaneous preterm labor, PPROM, antenatal hemorrhage, and maternal infection, was used as the reference category, whereas hypertensive disorders and IUGR were grouped together under the heading of disorders of placentation. Before adjustment for GA, disorders of placentation were associated with lower mortality and neurologic damage than presumed infection/inflammation. After adjustment for GA, an association emerged between disorders of placentation and increased risk of mortality (OR 1.4, 95\% confidence interval, CI 1.0-2.0), BPD (OR 2.5; 95\% CI 1.83.6), and ROP (OR 2.0; 95\% CI 1.1-3.5), whereas the lower risk of severe intraventricular hemorrhage (IVH) and cystic periventricular leukomalacia (PVL) remained almost unchanged.
This change of OR between GA-unadjusted and GA-adjusted analyses was checked by conducting the analyses in narrow strata of GA (Table 4). In the range of 23-29 wk, effects appear to be homogeneous. At 30-31 wk, especially for mortality and BPD, an apparent reversal or an attenuation of the effect was observed. Because the number of events was very small, we cannot be certain if the risk pattern is different at an older GA or if this is due to random fluctuations. On the whole, no statistically significant differences between strata were demonstrated for any outcome.

Finally, in the model adjusted also for age of the mother, nationality, maternal education, sex, and antenatal steroids prophylaxis, the association between disorders of placentation and mortality remained identical (OR 1.4, 95\% CI 1.02.1), as well as that with BPD (OR 2.5; 95\% CI 1.7-3.5), with severe IVH (OR 0.5, 95\% CI 0.3-0,8), and with cystic PVL (OR 0.7, 95\% CI 0.4-1.2), whereas the association with ROP (OR 1.7, 95\% CI 0.9-3.1) marginally tended toward the null value.

\section{DISCUSSION}

This study shows that very preterm infants born following different pathological processes leading to early birth have different profiles of risk of neonatal mortality and morbidity. Neonates of the infection/inflammation group had a lower GA and worse overall outcomes than those born following disorders of placentation. Once the sample is adjusted for GA, those born following maternal hypertension and IUGR present a higher risk of BPD, severe ROP and, particularly for IUGR, in-hospital mortality as compared with peers born following other conditions. By contrast, infection/inflammation is associated with higher risk of severe IVH/PVL. These results support the hypothesis that adverse neonatal outcomes after very preterm birth are both a function of immaturity, as measured by low GA, and of the pathological conditions leading to early delivery (1).

Although mortality of very preterm infants has been widely studied, scarce and conflicting data are available on the association between mortality and antecedents of preterm birth (2-6). Our study found, after adjustment for GA, an increased risk of death associated with disorders of placentation as compared with presumed infection/inflammation disorders. Infants in the disorders of placentation group were smaller than those born following infection/inflammation, and several studies have reported a higher mortality in small-for-GA (SGA) infants as compared with normally grown peers (e.g., refs. 3,13,14). IUGR seems to be the major driver of this risk: in our data, infants with IUGR had a greater risk than those born from hypertensive mothers; a similar finding was reported by McElrath and colleagues in their cohort of extremely preterm babies (3). It appears that when disorders of placentation lead to impairment of fetal growth, not only morbidity but also mortality is negatively influenced, even if low birth weight per se is probably not causally related to death (15). Moreover, intrauterine infection/inflammation activates stress pathways that may increase short-term adaptation and survival, possibly 
Table 2. Associations (ORs and $95 \% \mathrm{Cls}$ ) between antenatal complications and different outcomes

\begin{tabular}{|c|c|c|}
\hline & OR $(95 \% \mathrm{Cl})^{\mathrm{a}}$ & $\mathrm{OR}(95 \% \mathrm{Cl})^{\mathrm{b}}$ \\
\hline \multicolumn{3}{|l|}{ Mortality } \\
\hline Spontaneous preterm labor & 1 (reference) & 1 (reference) \\
\hline PPROM & $0.6(0.4-0.9)$ & $1.2(0.8-1.9)$ \\
\hline Hypertensive disorders & $0.3(0.2-0.5)$ & $1.0(0.6-1.6)$ \\
\hline IUGR & $0.7(0.5-1.1)$ & $3.1(1.9-5.5)$ \\
\hline Hemorrhage & $0.6(0.4-0.9)$ & $1.3(0.8-2.2)$ \\
\hline Maternal infection & $0.9(0.5-1.7)$ & $1.0(0.5-2.1)$ \\
\hline Suspected acute fetal distress & $0.3(0.1-0.8)$ & $1.5(0.4-5.1)$ \\
\hline Other & $0.5(0.2-1.3)$ & $0.9(0.3-2.9)$ \\
\hline Unknown & $0.7(0.3-1.6)$ & $1.3(0.3-3.9)$ \\
\hline \multicolumn{3}{|l|}{ IVH grade III-IV } \\
\hline Spontaneous preterm labor & 1 (reference) & 1 (reference) \\
\hline PPROM & $0.4(0.2-0.6)$ & $0.6(0.4-1.0)$ \\
\hline Hypertensive disorders & $0.2(0.1-0.3)$ & $0.3(0.2-0.6)$ \\
\hline IUGR & $0.2(0.1-0.5)$ & $0.6(0.3-1.4)$ \\
\hline Hemorrhage & $0.4(0.3-0.7)$ & $0.7(0.4-1.3)$ \\
\hline Maternal infection & $0.5(0.2-1.2)$ & $0.5(0.2-1.3)$ \\
\hline Suspected acute fetal distress & $0.4(0.1-1.2)$ & $1.0(0.3-3.5)$ \\
\hline Other & $0.5(0.2-1,6)$ & $0.9(0.3-2.7)$ \\
\hline Unknown & $0.9(0.4-2.2)$ & $1.2(0.5-3.3)$ \\
\hline \multicolumn{3}{|l|}{ Cystic PVL } \\
\hline Spontaneous preterm labor & 1 (reference) & 1 (reference) \\
\hline PPROM & $0.7(0.4-1.4)$ & $0.8(0.4-1.5)$ \\
\hline Hypertensive disorders & $0.5(0.3-0.9)$ & $0.6(0.3-1.2)$ \\
\hline IUGR & $0.4(0.2-1.0)$ & $0.5(0.2-1.3)$ \\
\hline Hemorrhage & $0.8(0.4-1.5)$ & $0.9(0.4-1.7)$ \\
\hline Maternal infection & $1.0(0.4-2.8)$ & $1.0(0.4-2.7)$ \\
\hline Suspected acute fetal distress & $1.1(0.3-3.5)$ & $1.4(0.4-4.7)$ \\
\hline Other & $1.3(0.5-3.9)$ & $1.7(0.6-5.0)$ \\
\hline Unknown & $1.5(0.5-4.7)$ & $1.8(0.6-5.8)$ \\
\hline \multicolumn{3}{|l|}{ BPD } \\
\hline Spontaneous preterm labor & 1 (reference) & 1 (reference) \\
\hline PPROM & $0.7(0.5-1.1)$ & $1.1(0.6-1.8)$ \\
\hline Hypertensive disorders & $1.0(0.7-1.5)$ & $2.6(1.6-4.1)$ \\
\hline IUGR & $1.2(0.7-1.9)$ & $3.6(2.1-6.4)$ \\
\hline Hemorrhage & $0.8(0.5-1.3)$ & $1.5(0.9-2.6)$ \\
\hline Maternal infection & $1.1(0.5-2.4)$ & $1.0(0.5-2.4)$ \\
\hline Suspected acute fetal distress & $0.9(0.4-2.4)$ & $2.9(1.1-7.6)$ \\
\hline Other & $0.7(0.2-2.0)$ & $1.6(0.5-5.2)$ \\
\hline Unknown & $1.3(0.5-3.3)$ & $2.1(0.7-6.2)$ \\
\hline \multicolumn{3}{|l|}{ ROP stage $3-4$ or plus } \\
\hline Spontaneous preterm labor & 1 (reference) & 1 (reference) \\
\hline PPROM & $0.7(0.4-1.3)$ & $1.1(0.5-2.1)$ \\
\hline Hypertensive disorders & $0.7(0.4-1.2)$ & $2.0(1.0-4.0)$ \\
\hline IUGR & $0.4(0.1-1.0)$ & $1.4(0.5-3.8)$ \\
\hline
\end{tabular}

Table 2. Continued

\begin{tabular}{lll}
\hline & $\mathrm{OR}(95 \% \mathrm{Cl})^{\mathrm{a}}$ & $\mathrm{OR}(95 \% \mathrm{Cl})^{\mathrm{b}}$ \\
\hline Hemorrhage & $0.3(0.1-0.8)$ & $0.5(0.2-1.5)$ \\
Maternal infection & $0.9(0.3-2.7)$ & $0.7(0.2-2.2)$ \\
Suspected acute fetal distress & $0.4(0.1-1.1)$ & $1.4(0.5-3.9)$ \\
Other & $0.3(0.1-2.7)$ & $0.9(0.1-7.3)$ \\
Unknown & $0.5(0.1-3.2)$ & $0.7(0.1-4.3)$ \\
\hline
\end{tabular}

Generalized estimating equations taking into account clustering for hospital.

BPD, bronchopulmonary dysplasia; $\mathrm{Cl}$, confidence interval; IUGR, intrauterine growth restriction; IVH, intraventricular hemorrhage; OR, odds ratio; PPROM, prelabor

premature rupture of membranes; PVL, periventricular leukomalacia; ROP, retinopathy of prematurity.

aORs adjusted for level of birth center. ${ }^{\mathrm{b} O R s}$ adjusted for level of birth center and gestational age.

Table 3. Associations (ORs and $95 \% \mathrm{Cls}$ ) between "disorders of placentation"group (hypertensive disorders and IUGR) and different outcomes

\begin{tabular}{lll}
\hline & $\mathrm{OR}(95 \% \mathrm{Cl})^{\mathrm{a}}$ & $\mathrm{OR}(95 \% \mathrm{Cl})^{\mathrm{b}}$ \\
\hline Mortality & $0.5(0.4-0.7)$ & $1.4(1.0-2.0)$ \\
IVH grade III-IV & $0.3(0.2-0.4)$ & $0.5(0.3-0.8)$ \\
Cystic PVL & $0.5(0.3-0.9)$ & $0.6(0.4-1.1)$ \\
BPD & $1.2(0.9-1.6)$ & $2.5(1.8-3.6)$ \\
ROP stage 3-4 or plus & $0.8(0.5-1.3)$ & $2.0(1.1-3.5)$ \\
\hline
\end{tabular}

Generalized estimating equations taking into account clustering.

BPD, bronchopulmonary dysplasia; $\mathrm{Cl}$, confidence interval; IUGR, intrauterine growth restriction; IVH, intraventricular hemorrhage; OR, odds ratio; PPROM, prelabor premature rupture of membranes; $P V L$, periventricular leukomalacia; $R O P$, retinopathy of prematurity.

"ORs adjusted for level of birth center; reference category is "Infection/Inflammation" group (spontaneous preterm labor, PPROM, hemorrhage, and maternal infection). 'ORs adjusted for level of birth center and gestational age; reference category is "Infection/ Inflammation" group (spontaneous preterm labor, PPROM, hemorrhage, and maternal infection).

through the modulating effects of cytokines on surfactant synthesis, with accelerated lung maturation and prevention of respiratory distress syndrome (16). Indeed, in our population, $48.7 \%$ of deaths occurred in the first $5 \mathrm{~d}$ of life, largely due to respiratory causes, and respiratory distress syndrome was more common in the hypertensive than in the presumed infection/inflammation group $(\mathrm{OR}=1.41,95 \%$ CI 1.1-1.8, adjusted for GA, sex, and antenatal steroids).

In recent years, great attention has been paid to the adverse effects of intrauterine infection, mainly chorioamnionitis, on neonatal lung and brain, and the association between antenatal infection and cerebral white matter damage has gained wide acceptance $(17,18)$. Our findings corroborate the association between infection/inflammation and ultrasound-diagnosed cerebral lesions. Of interest, the increase in risk due to infection as compared with placentation disorders is not limited to PVL, but extends also to IVH. Although these two entities are often regarded as having different risk factors and pathogenesis, they frequently co-occur, and IVH might represent a causal factor for PVL (19).

The long-term effect of infection on the lung is more disputed. It has been suggested that the activation of inflammatory 


\section{Articles | Gagliardi et al.}

Table 4. Associations (ORs and $95 \% \mathrm{Cls}$ ) between "disorders of placentation" group (hypertensive disorders and IUGR) and different outcomes in strata of GA weeks

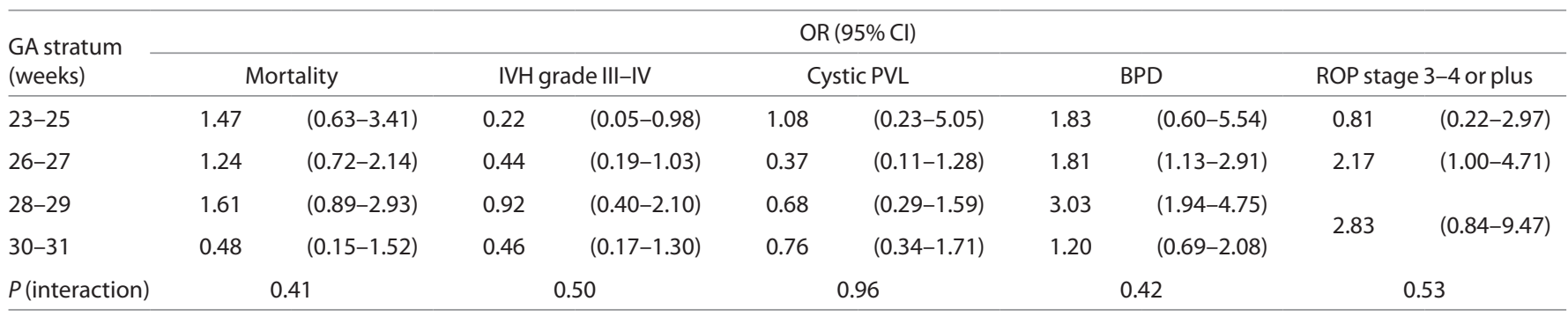

ORs adjusted for level of birth center. Reference category is"Infection/Inflammation" group (spontaneous preterm labor, PPROM, hemorrhage, and maternal infection).

BPD, bronchopulmonary dysplasia; Cl, confidence interval; GA, gestational age; IUGR, intrauterine growth restriction; IVH, intraventricular hemorrhage; OR, odds ratio; PPROM, prelabor premature rupture of membranes; $\mathrm{PVL}$, periventricular leukomalacia; ROP, retinopathy of prematurity.

pathways, while reducing respiratory distress syndrome, may increase BPD (20). Two recent systematic reviews, however, reached partly different conclusions; one (21) (also confirmed by other studies) $(7,22)$ found no relationship between histological chorioamnionitis and BPD, whereas the other suggested a possible harmful effect (23). In our data, once GA was taken into account, BPD did not appear to be associated with inflammatory causes of delivery but rather with placentation disorders. The effect of preeclampsia on BPD is disputed (710 ), with a population-based study in Australia and accompanying meta-analysis refuting the association (9), but with two recent single-center studies not included in the meta-analysis $(7,10)$ lending support to the "vascular hypothesis" of BPD. It is known that an array of circulating antiangiogenic factors might play a role in preeclampsia and SGA (24) and could represent the link between abnormal placentation and a pathological development of lung blood vessels (25). Of note, in our study, when the effect of the two main clinical presentations of placentation disorders (IUGR and hypertensive disease) was examined separately in comparison with spontaneous labor, the OR for IUGR (3.6) was higher than that for hypertensive disorders (2.6). It is known that SGA infants, a category largely caused by and overlapping with IUGR, are at increased risk of $\operatorname{BPD}(7,13,14,26)$. Recent data from a large prospective cohort showed that SGA is also associated with a poorer lung function in childhood among term infants, possibly linking infant size with lung size (27). Our results therefore support the hypothesis that pathogenetic mechanisms involving the regulation of lung/airways size and vessels are quantitatively more important than "inflammatory" ones in the development of BPD.

The results for ROP were very similar to those found for $\mathrm{BPD}$, suggesting that mechanisms such as paucity of angiogenic factors may be common to these two conditions. Being SGA has been repeatedly shown to be a risk factor for severe ROP $(28,29)$.

The interpretation of associations found in the current study requires a clarification. It is accepted that all pathways that lead to preterm delivery are pathological, hence, comparisons are between pathologic groups. An OR of hypertensive disorders significantly below 1 for severe IVH, as found in this study, should not lead to the conclusion that maternal hypertension is "protective" toward this outcome. Rather, the decreased risk arises from comparison with a group of infants with a different but stronger risk factor, namely infection/inflammation.

A second point to be discussed concerns the adjustment for GA, which in our study modified the strength and in some cases (i.e., mortality, BPD, and ROP) even the direction of the association between exposure and outcome. According to our data, GA was differentially associated with the pregnancy complications leading to preterm delivery and was a strong predictor of outcomes. Adjustment for GA is widely used in observational studies examining predictors of neonatal outcomes after preterm birth $(2-7,9,10,30)$. Yet this approach is not uncontroversial and can lead to biased conclusions (31). Neonatal adverse outcomes depend both on immaturity (low GA), and on the conditions that caused preterm birth (1). Therefore, very low GA would represent both a risk factor per se and a mediator in the causal pathway linking cause of preterm birth to outcome. However, adjustment for an intermediate variable might introduce bias (1,31-33), unless all mediator-outcome confounders are taken into account in the analysis. The difficulty of achieving - at least at the current level of knowledge of etiology of preterm birth-full control of all mediator-outcome confounders limits the possibility of causal interpretation of the associations found but not their descriptive value (34). This is a problem common to all observational outcome studies of preterm infants. Our conclusions are further strengthened by the consistency of results when other potential confounders of the mediator-outcome (namely, nationality, maternal age, education, and antenatal steroids) are taken into account.

Some limitations of this study should be noted. The identification of the main event leading to preterm birth was carried out by clinicians and, despite using an accepted classification and predetermined categories, a certain level of misclassification cannot be excluded given the large number of participating centers. We did not collect data on placental histology/microbiology, therefore the "infectious" causes remain unproven. However, grouping different causes into larger groups may help overcome this problem.

Only liveborn infants were included in this analysis. To assess the overall contribution of each complication to the risk of death, we should have also had area-based information on stillbirths. Unfortunately, we did not collect this information, and therefore we cannot test the hypothesis. If cesarean 
section is performed less frequently in very immature fetuses, this would increase stillbirths and decrease mortality in liveborn infants, especially in the placentation disorders group, in which cesarean section is the rule. This would probably underestimate mortality risk in placentation disorders, yielding conservative estimates of the relative risk.

The same caveat might apply also to neonates born alive at the threshold of viability, if differentially resuscitated and transferred to intensive care. However, previous studies have shown that in Italy, withholding resuscitation at birth is uncommon (35). In our sample, only 30 neonates died in the delivery room, and no evidence of such an effect exists. It should be noted that this potential bias refers only to mortality, not to other outcomes, which are defined only in liveborn infants.

In summary, our results suggest that in very preterm infants, different complications leading to preterm delivery are differentially linked to outcomes. The associations between a given complication and several different outcomes (e.g., BPD, ROP) point to common mechanisms that are worth investigation.

Finally, we strongly support the view (36) that large multicenter studies, taking into consideration the full spectrum of causes of preterm deliveries, are necessary to reconcile divergent findings in literature and that "studies that intensely focus on small subsets of patients with specific clinical or pathological findings such as histologic inflammation or hypertension may be relatively underpowered statistically, and may miss a unifying physiology" (36). In addition to more stable results and greater power, multicenter studies avoid the risk that within single institutions, policies of treatment would increase or spuriously produce associations between variables. We hope that our study contributes to the emerging debate about the classification of the preterm birth syndrome $(3,11,36,37)$, with the aim of clarifying its causes, epidemiology, and consequences.

\section{METHODS}

\section{Design and Study Population}

The ACTION project was a prospective population-based cohort study, carried out in six Italian regions: two in northern (Lombardia and Friuli-Venezia Giulia), three in central (Toscana, Marche, and Lazio), and one in southern Italy (Calabria). These regions cover $\sim 40 \%$ of all births in Italy.

The cohort included all liveborn infants of 22-31 wk GA admitted to neonatal care between July 2003 and December 2004 in Lombardia, Lazio, and Calabria, and up to June 2005 in the other regions. A standardized structured form was used to collect information on maternal data, obstetrical history and preperinatal care, morbidities and treatments during the hospital stay, and health status at $36 \mathrm{wk}$ postmenstrual age and at discharge from hospital. Prenatal care in Italy is free of charge even for nonregular immigrants, and virtually all pregnant women adhere to the routine antenatal care program starting in early pregnancy.

This study concerns liveborn singleton infants of 23-31 wk GA. Twenty-three infants born at $22 \mathrm{wk}$ GA were excluded because their mortality was so high irrespective of causes of birth that they would not add information to the analysis. Twins (853) were excluded because their pattern of complications are possibly different from singletons. Finally, 50 infants with lethal/life-threatening congenital anomalies and 29 with anomalies (ocular, cerebral, or pulmonary) possibly affecting the outcomes under study were also excluded. Ethics committee (Burlo Garofolo Children's Hospital, Trieste, Italy) approval and written parental consent were obtained.

\section{Antecedents of Preterm Birth}

Clinicians involved in the study identified the main antenatal complication that started the train of events leading to delivery. The following a priori-defined mutually exclusive categories, derived from the Australian New Zealand Neonatal Network (http://www.npsu.unsw. edu.au/preruweb.nsf/page/ANZNN), were used:

1. Spontaneous preterm labor: regular painful contractions, eventually leading to the preterm birth of the baby;

2. PPROM: confirmed spontaneous rupture of membranes occurring before the onset of labor;

3. Pregnancy hypertensive disorders: systolic blood pressure $>140 \mathrm{~mm} \mathrm{Hg}$ and/or diastolic pressure $>90 \mathrm{~mm} \mathrm{Hg}$, or preeclampsia, or hemolysis, elevated liver enzymes, low platelets syndrome;

4. Antepartum hemorrhage;

5. IUGR: a condition in which the fetus fails to reach its full growth potential, based on obstetric ultrasounds;

6. Maternal infection as an indication for delivery;

7. Suspected acute fetal distress: any fetal "distress" leading to intervention by the obstetric team;

8. Other identified causes, including prenatal diagnosis of malformation.

Among 426 cases of suspected acute fetal distress, multiple antenatal complications, or missing or "open" answers, the main antenatal complication leading to preterm delivery was identified on the basis of additional information derived from other parts of the questionnaire (complications during pregnancy, modality and onset of labor, mode of delivery, and duration of PPROM, if any), by consensus between three of us (L.G., F.R., and G.M.), who were blinded to outcomes. When both hypertension/hemolysis, elevated liver enzymes, low platelets, and IUGR were present, the case was attributed to hypertension. For 43 babies, we were unable to identify the main antenatal complication (39 missing answers, and 4 nonconfirmed malformations), whereas for 47 newborns, suspected acute fetal distress was the only diagnostic label.

Antenatal complications of preterm delivery defined above were subsequently grouped into "disorders of placentation" (hypertensive disorders and IUGR) and "intrauterine inflammation/infection" (spontaneous preterm delivery, PPROM, maternal infection, and antepartum hemorrhage), as suggested by McElrath et al. (3).

\section{Outcomes}

The following neonatal outcomes were considered: in-hospital death; grade III-IV IVH (38); cystic PVL, defined as the presence of one or more periventricular white matter echolucencies (39); stage III-IV $\mathrm{ROP}$, defined as the presence of a ridge with fibro-vascular extraretinic proliferation, or retinal detachment, or "plus" (40); BPD, defined as the need for oxygen supplementation at $36 \mathrm{wk}$ postmenstrual age or at discharge for infants discharged earlier.

\section{Statistical Analysis}

Descriptive statistics employed $\chi^{2}$ test and ANOVA. The relationship between causes of preterm birth and outcomes was analyzed through multivariable logistic models using generalized estimating equations to take into account the two-level structure (hospitals and neonates) of the database. Associations were expressed as ORs and 95\% CIs. Four hierarchical models were constructed for each outcome variable. The first model included only the exposure variable (antecedent of preterm birth) and place of birth (tertiary vs. nontertiary center) as predictors. The second model adjusted also for week of GA (as a categorical variable), and the third additionally included sex and antenatal steroid prophylaxis (any steroids vs. none). In the fourth model, we added a number of other potential confounders: age of the mother ( $<25 \mathrm{y} ; 25-34 \mathrm{y} ;>35 \mathrm{y})$, nationality (Italian/foreign), and maternal education $(\leq 8 \mathrm{y} ;>8 \mathrm{y})$. Moreover, given the difference in models adjusting for GA and those not, the analyses were repeated in narrow strata of GA to detect gross changes in the direction of the OR across strata.

All analyses were carried out with the package Stata 10 (Stata, College Station, TX). 


\section{APPENDIX}

Main participants in the ACTION project

Friuli-Venezia Giulia

Istituto per l'Infanzia "Burlo Garofolo," Trieste (S. Alberico, S. Demarini, S. Guaschino, I. Redaelli, V. Soini, F. Uxa); Santa Maria della Misericorda University Hospital, Udine (R. Da Riol, F. Macagno, D. Marchesoni, A. Pontrelli, A. Rossi); Azienda Ospedialiera Santa Maria degli Angeli, Pordenone (V. Adamo, A. Bordugo, M. Fadalti, L. Peratoner).

$\underline{\text { Lombardia }}$

Ospedali Riuniti, Bergamo (G. Burgio, A. Colombo); Spedali Civili, Brescia (A. Cavazza, G. Chirico, R. Marzollo); Ospedale Valduce, Como (F. Frisone, M. Maccabruni); Ospedale S. Anna, Como (L. Caccamo, P. Faldini, D. Merazzi, L. Rossi); Ospedale A. Manzoni, Lecco (R. Bellù, S. De Poli, R. Zanini); Ospedale Fornaroli, Magenta Mi (A. Avanzino, S. Barp, R. Crossignani, S. Santucci); Ospedale San Raffaele, Milano (G. Barera, D. Cella, L. Moiraghi); Ospedale Buzzi, Milano (M. Battaglioli, G. Compagnoni); Fondazione IRCCS "Ca' Granda" Ospedale Maggiore Policlinico di Milano", Milano (P. Bastrenta, F. Mosca); Ospedale Niguarda, Milano (A. Brunelli, S. Martinelli); Presidio Ospedaliero M. Melloni, Milano (M. Franco, G. Moro); Ospedale S. Gerardo, Monza (P. Tagliabue, M.L. Ventura); Ospedale Salvini, Rho Mi (R. Germani, L. Magni, M. Pelti); IRCCS Policlinico San Matteo, Pavia (G.F. Perotti, E. Polito); Ospedale Bolognini, Seriate (M. Felice, S. Ferrari, M. Somaschini); Ospedale di Circolo, Varese (M. Agosti, G. Citterio, P. Guidali).

Toscana

Ospedali Riuniti S. Chiara Azienda Ospedaliero-Universitaria Pisana, Pisa (A. Boldrini, P. Bottone, A. Carmignani, V. Facchini, A.R. Genazzani, L. Giardina, C. Maggi, E. Sigali, F. Strigini); Ospedale Unico della Versilia, Lido di Camaiore (L. Gagliardi, A. Marchetti, I. Merusi, G. Ternelli); Ospedale SS. Cosimo Damiano, Pescia (R. Agostiniani, F. Bray, M.L. Demuru, L. Niccoli); Ospedale Misericordia e Dolce, Prato (U. Bottone, P. Ciolini, P. Dal Poggetto, L. Golin, E. Martelli); Nuovo Ospedale S.G. di Dio Torregalli, Firenze (L. Berti, C. Guerri, M. Pezzati, M. Strano, S. Tofani); Azienda Ospedaliero-Universitaria Careggi, Firenze (G. Bertini, C. Dani, M. Marchionni, G. Mello, S. Perugi, S. Rossi, F. Rubaltelli, G. Scarselli, F. Tondi); Ospedale S.M. Annunziata, Bagno a Ripoli (G. Assenza, F. Barciulli, C. Campatelli, D. Pettini, F. Romoli); Ospedale Le Scotte Azienda Ospedaliero-Universitaria, Siena (A. Annesanti, F. Bagnoli, G. Bonocore, P. Marenzoni, F. Pietraglia, E. Piccolini); Ospedale S. Donato, Arezzo (L. Burroni, F. Catania, G. Cristini, G. D’Ascola, M. Paccariè).

Marche

Ospedale di Macerata, Macerata (E. Garbati, A. Mercuri, L. Palombi, P. Perri); Azienda Ospedaliera Salesi, Ancona (V. Bazzeccheri, R. Buglia, V. Carnielli, C. Civitella, F. Del Savio, R. Freddara, L. Pellegrini, A.L. Tranquilli).

$\underline{\text { Lazio }}$

S.G. Calibita-Fatebenefratelli, Roma (A. De Santis, E. Pontesilli, A. Sacco); Policlinico Casilino, Roma (M.C. De Marco, C. Leo); Sandro Pertini, Roma (A. Andreuzzi, E. Giorgi);
Giovanni Battista Grassi, Roma (M. Bonci, C. Trivellini); S. Pietro Fatebenefratelli, Roma (M. Barresi, R. Maruccio, P. Paesano, E. Scapillati); San Camillo, Roma (P. Favata, G. Pellegrini, F. Pierucci, G. Scassellati, F. Signore, Ottaviano Carla); San Filippo Neri, Roma (S. Anania, R. Balestrieri, S. Cucuzzoli, M. Matone, F. Valentini); San Giovanni, Roma (I. Bezzi, F. Marchetti); IRCCS Bambino Gesù, Roma (C. Auriti, S. Lozzi, S. Palamides, N. Pirozzi); Policlinico Gemelli, Roma (S. Costa, C. Dell'Aquila, E. Zecca); Policlinico Umberto I, Roma (R. Aufieri, P. Ciolli, R. Lucchini, R. Paesano, A. Panero, M.G. Villani); Sant'Eugenio, Roma (L. Cristini, A. Di Paolo, P. Ndenga, C. Ticconi); San Giovanni Evangelista, Tivoli (A. Leodori, M. Marceca, D. Marini); Generale Provinciale, Anzio (V. Ambrogi, A. Faiola, R. la Rocca); Umberto I, Frosinone (G. Palermo, M.R. Pecci, S. Tambucci); Belcolle, Viterbo (S. Bracaloni, F. Ciripicchia, K. Colella, L. Dattis, R. Navas).

\section{Calabria}

Azienda Ospedaliera Pugliese-Ciaccio, Catanzaro (S. Miniaci, V. Pascale); Azienda Ospedaliera dell'Annunziata, Cosenza (A. Contaldo, C. Corchia); Presidio Ospedaliero San Giovanni di Dio, Crotone (U. Corapi, C. Crugliano); Presidio Ospedaliero di Lamezia Terme, Lamezia Terme (S.A. Canepa, G. Scozia); Azienda Ospedaliera Bianchi-Melacrino-Morelli, Reggio Calabria (R. Cimellaro, G. Fontanelli, A. Nicolò).

\section{ACKNOWLEDGMENTS}

Hospitals and participants in the ACTION project have been listed in the Appendix. This article is affectionately dedicated to Eva Buiatti. As chief of the Epidemiological Section of the Regional Health Agency of Tuscany, she was, until her untimely death, a continuing source of inspiration and of generous support to this project.

\section{STATEMENT OF FINANCIAL SUPPORT}

The project was funded by the Italian Ministry of Health (Programma di Ricerca Finalizzata 2004) and coordinated by the Unit of Epidemiology of the Regional Agency for Health of Tuscany. The sponsor had no part in the design and conduct of the study; collection, management, analysis, interpretation of the data; or preparation, review, or approval of the manuscript.

Disclosure: The authors declared no conflicts of interest.

\section{REFERENCES}

1. Basso O, Wilcox A. Mortality risk among preterm babies: immaturity versus underlying pathology. Epidemiology 2010;21:521-7.

2. Baud O, Zupan V, Lacaze-Masmonteil T, et al. The relationships between antenatal management, the cause of delivery and neonatal outcome in a large cohort of very preterm singleton infants. BJOG 2000;107: $877-84$.

3. McElrath TF, Hecht JL, Dammann O, et al.; ELGAN Study Investigators. Pregnancy disorders that lead to delivery before the 28th week of gestation: an epidemiologic approach to classification. Am J Epidemiol 2008;168:980-9.

4. Villar J, Abalos E, Carroli G, et al.; World Health Organization Antenatal Care Trial Research Group. Heterogeneity of perinatal outcomes in the preterm delivery syndrome. Obstet Gynecol 2004;104:78-87.

5. Chen XK, Wen SW, Smith G, Yang Q, Walker M. Pregnancy-induced hypertension is associated with lower infant mortality in preterm singletons. BJOG 2006;113:544-51.

6. Foix-L’helias L, Baud O, Lenclen R, Kaminski M, Lacaze-Masmonteil T. Benefit of antenatal glucocorticoids according to the cause of very premature birth. Arch Dis Child Fetal Neonatal Ed 2005;90:F46-8. 
7. Bose C, Van Marter LJ, Laughon M, et al.; Extremely Low Gestational Age Newborn Study Investigators. Fetal growth restriction and chronic lung disease among infants born before the 28th week of gestation. Pediatrics 2009;124:e450-8.

8. Hansen AR, Barnés CM, Folkman J, McElrath TF. Maternal preeclampsia predicts the development of bronchopulmonary dysplasia. J Pediatr 2010;156:532-6.

9. O'Shea JE, Davis PG, Doyle LW; Victorian Infant Collaborative Study Group. Maternal preeclampsia and risk of bronchopulmonary dysplasia in preterm infants. Pediatr Res 2012;71:210-4.

10. Durrmeyer X, Kayem G, Sinico M, Dassieu G, Danan C, Decobert F. Perinatal risk factors for bronchopulmonary dysplasia in extremely low gestational age infants: a pregnancy disorder-based approach. J Pediatr 2012;160:578-583.e2.

11. Kramer MS, Papageorghiou A, Culhane J, et al. Challenges in defining and classifying the preterm birth syndrome. Am J Obstet Gynecol 2012;206:108-12.

12. Klebanoff MA, Shiono PH. Top down, bottom up and inside out: reflections on preterm birth. Paediatr Perinat Epidemiol 1995;9: $125-9$.

13. Lal MK, Manktelow BN, Draper ES, Field DJ; Population-based study. Chronic lung disease of prematurity and intrauterine growth retardation: a population-based study. Pediatrics 2003;111:483-7.

14. Zeitlin J, El Ayoubi M, Jarreau PH, et al.; MOSAIC Research Group. Impact of fetal growth restriction on mortality and morbidity in a very preterm birth cohort. J Pediatr 2010;157:733-9.e1.

15. Basso O, Wilcox AJ, Weinberg CR. Birth weight and mortality: causality or confounding? Am J Epidemiol 2006;164:303-11.

16. Lahra MM, Beeby PJ, Jeffery HE. Maternal versus fetal inflammation and respiratory distress syndrome: a 10-year hospital cohort study. Arch Dis Child Fetal Neonatal Ed 2009;94:F13-6.

17. Dammann O, Leviton A. Maternal intrauterine infection, cytokines, and brain damage in the preterm newborn. Pediatr Res 1997;42:1-8.

18. Wu YW, Colford JM Jr. Chorioamnionitis as a risk factor for cerebral palsy: A meta-analysis. JAMA 2000;284:1417-24.

19. Kusters CD, Chen ML, Follett PL, Dammann O. "Intraventricular" hemorrhage and cystic periventricular leukomalacia in preterm infants: how are they related? J Child Neurol 2009;24:1158-70.

20. Watterberg KL, Demers LM, Scott SM, Murphy S. Chorioamnionitis and early lung inflammation in infants in whom bronchopulmonary dysplasia develops. Pediatrics 1996;97:210-5.

21. Been JV, Zimmermann LJ. Histological chorioamnionitis and respiratory outcome in preterm infants. Arch Dis Child Fetal Neonatal Ed 2009;94:F218-25.

22. Lahra MM, Beeby PJ, Jeffery HE. Intrauterine inflammation, neonatal sepsis, and chronic lung disease: a 13-year hospital cohort study. Pediatrics 2009;123:1314-9.

23. Hartling L, Liang Y, Lacaze-Masmonteil T. Chorioamnionitis as a risk factor for bronchopulmonary dysplasia: a systematic review and meta-analysis. Arch Dis Child Fetal Neonatal Ed 2012;97:F8-F17.
24. Levine RJ, Maynard SE, Qian C, et al. Circulating angiogenic factors and the risk of preeclampsia. N Engl J Med 2004;350:672-83.

25. Thébaud B, Lacaze-Masmonteil T. If your placenta doesn't have it, chances are your lungs don't have it either: the "vascular hypothesis" of bronchopulmonary dysplasia starts in utero. J Pediatr 2010;156:521-3.

26. Gagliardi L, Bellù R, Zanini R, Dammann O; Network Neonatale Lombardo Study Group. Bronchopulmonary dysplasia and brain white matter damage in the preterm infant: a complex relationship. Paediatr Perinat Epidemiol 2009;23:582-90.

27. Kotecha SJ, Watkins WJ, Heron J, Henderson J, Dunstan FD, Kotecha S. Spirometric lung function in school-age children: effect of intrauterine growth retardation and catch-up growth. Am J Respir Crit Care Med 2010;181:969-74.

28. Dhaliwal CA, Fleck BW, Wright E, Graham C, McIntosh N. Retinopathy of prematurity in small-for-gestational age infants compared with those of appropriate size for gestational age. Arch Dis Child Fetal Neonatal Ed 2009;94:F193-5.

29. Darlow BA, Hutchinson JL, Henderson-Smart DJ, Donoghue DA, Simpson JM, Evans NJ; Australian and New Zealand Neonatal Network. Prenatal risk factors for severe retinopathy of prematurity among very preterm infants of the Australian and New Zealand Neonatal Network. Pediatrics 2005;115:990-6.

30. Ancel PY, Marret S, Larroque B, et al.; Epipage Study Group. Are maternal hypertension and small-for-gestational age risk factors for severe intraventricular hemorrhage and cystic periventricular leukomalacia? Results of the EPIPAGE cohort study. Am J Obstet Gynecol 2005;193:178-84.

31. Hernández-Díaz S, Schisterman EF, Hernán MA. The birth weight "paradox" uncovered? Am J Epidemiol 2006;164:1115-20.

32. Wilcox AJ, Weinberg CR, Basso O. On the pitfalls of adjusting for gestational age at birth. Am J Epidemiol 2011;174:1062-8.

33. VanderWeele TJ, Hernández-Diaz S. Is there a direct effect of pre-eclampsia on cerebral palsy not through preterm birth? Paediatr Perinat Epidemiol 2011;25:111-5.

34. Gagliardi L. Prediction and causal inference. Acta Paediatr 2009;98:18902.

35. Cuttini M, Casotto V, Orzalesi M; Euronic Study Group. Ethical issues in neonatal intensive care and physicians' practices: a European perspective. Acta Paediatr Suppl 2006;95:42-6.

36. McElrath TF, Hecht JL. Invited commentary: Intrauterine epidemiology. Am J Epidemiol 2009;170:159-61; discussion 162-3.

37. Villar J, Papageorghiou AT, Knight HE, et al. The preterm birth syndrome: a prototype phenotypic classification. Am J Obstet Gynecol 2012;206:119-23.

38. Papile LA, Burstein J, Burstein R, Koffler H. Incidence and evolution of subependymal and intraventricular hemorrhage: a study of infants with birth weights less than 1,500 gm. J Pediatr 1978;92:529-34.

39. de Vries LS, Eken P, Dubowitz LM. The spectrum of leukomalacia using cranial ultrasound. Behav Brain Res 1992;49:1-6.

40. International Committee for the Classification of Retinopathy of Prematurity. An international classification of retinopathy of prematurity. Pediatrics $1984 ; 74: 127-33$. 